\title{
Concurrent cisplatin, continuous infusion fluorouracil and radiotherapy followed by tailored consolidation treatment in non metastatic anal squamous cell carcinoma
}

\author{
Maria G Zampino ${ }^{1 *}$, Elena Magni ${ }^{1}$, Maria C Leonardi ${ }^{2}$, Luigi Santoro ${ }^{3}$, Elena Petazzi $^{2}$, Cristiana Fodor $^{2}$,
} Giuseppe Petralia ${ }^{4}$, Cristina Trovato $^{5}$, Franco Nolè ${ }^{1}$, Roberto Orecchia ${ }^{2,6}$

\begin{abstract}
Background: To evaluate efficacy and feasibility of chemo-radiotherapy in patients with non-metastatic anal squamous-cell-cancer.

Methods: TNM staged anal squamous-cell cancer patients were treated with pelvic radiotherapy concomitant to continuous infusion fluorouracil plus cisplatin for at least 2 cycles. In T3-T4 or any T - N+ tumours or in "slowresponder" cases, 1-2 chemotherapy courses were subsequently administered. Tumour assessment was performed at baseline and 6-8 weeks after radiotherapy to evaluate response.

Results: 29 patients were enrolled: 4 males, 25 females; median age 57 years; baseline T1/T2/T3/T4 2/12/7/8; N involvement 17. Median dose pelvic radiotherapy was 59.4 Gy (range: 54-74). In 5 patients 2 chemotherapy courses, in 12 patients three and in 12 patients four courses were performed. At first evaluation, 27 CR (93.1\%; 95\% Cl: 78\% - 98\%) and 2 SD were observed. Main grade (G) 3 toxic events were neutropenia (8\%), diarrhoea (8\%) and dermatitis (62\%). Most frequent late events G3-G4 occurred in 14 patients: proctitis (5), dermatitis (4), bladder dysfunctions (2), sexual dysfunctions (9), lower extremity venous thromboses (2), dysuria (1), stenosis (1) and tenesmus (1). Five patients reported G1 leucopoenia. The rate of colostomy was $14 \%$. After a median follow up of 42 months (range: 4-81), 20 patients are still alive without relapse and 3 died due to PD. The estimated 7-year DFS was 83.4\% (C.I.: 68.3\%-98.5\%) and the estimated 7-year OS was 85.7\% (C.I.: 70\% - 100\%). The 1-year and the estimated 7-year colostomy-free survivals were $85.9 \%$ (C.I.: $73.1 \%-98.7 \%$ ).

Conclusions: Concurrent cisplatin plus fluorouracil and radiotherapy is associated with favourable local control rates and acute toxicity. Future investigations will be directed towards research into molecular biomarkers related to disease progression and resistance to chemo-radiotherapy and to the evaluation of new cytotoxic agents or targeted drugs, such as anti-epidermal growth factor receptor, concomitant to RT and to determining the role of intensity-modulated radiotherapy.
\end{abstract}

\footnotetext{
* Correspondence: maria.zampino@ieo.it

'Medical Care Unit, Department of Medicine, European Institute of

Oncology, via Ripamonti 435, Milan 20141, Italy

Full list of author information is available at the end of the article
} 


\section{Background}

Anal carcinoma is an uncommon disease that represents approximately $1 \%$ of all gastrointestinal malignancies with increasing incidence over the past 25 years. Risk factors include HPV-infection, immune depressionsuppression, and smoking. Loco-regional progression often occurs while metastatic potential is present in $15 \%$ of patients [1]. Localized stage and a radio-chemotherapeutic sensitive tumour represent favourable conditions suitable to curative non-surgical treatment. The conventional approach with external-beam radiation therapy (RT) with concomitant fluorouracil (FU) and mitomycin (M) has induced successful disease control in two thirds of patients [2]. An anal lesion size greater than $5 \mathrm{~cm}$ and regional node involvement are two clinical features that have resulted in a reduction of the cure rate (local control 50-60\%) and worst outcome; a more aggressive approach is needed in this setting of patients [3]. With the aim of increasing objective response and reducing haematologic toxicity related to $M$, cisplatin $(C)$ was investigated in clinical trials, due to its property as radiation sensitizer and its therapeutic potential in squamocellular histology, and the interesting results also seen in anal cancer. But the optimal duration and the best chemotherapy-combination containing $C$, have not been yet determined. Our mono-institutional phase II trial aimed to evaluate FU as continuous infusion (c.i.) plus $C$ in patients affected by non-metastatic anal squamous cell cancer (SCC) with primary tumours larger than $2 \mathrm{~cm}$. The number of cycles was tailored on baseline patients characteristics and tumour response at the end of RT: one or two additional courses after RT were planned in high risk patients with $\mathrm{T}>5 \mathrm{~cm}$ and/or node-positive disease at baseline or in cases of persistence of primary lesion with regression $<50 \%$ (slow responders) at the end of $\mathrm{RT}$. The rationale of such a strategy was justified by early use of radiotherapy combined with radiosensitive agents and also in order to evaluate the role of systemic therapy if administered after the end of radiotherapy.

Primary goals were complete remission (CR) and disease-free survival (DFS) and secondary aims were colostomy rate and overall survival (OS).

\section{Methods}

\section{Patients and inclusion criteria}

We undertook a prospective study with chemo-radiotherapy, in patients affected by T2-T4 anal carcinoma or any $\mathrm{T}$ with locoregional positive nodes. Eligibility criteria included: histologically proven anal squamous cell carcinoma, age $\geq 18$ years, ECOG performance status $\leq 2$, adequate haematological, liver and renal function (granulocyte count $>1500 / \mathrm{mm}^{3}$, platelet count
$>100000 / \mathrm{mm}^{3}$, haemoglobin $>10 \mathrm{~g} / \mathrm{dl}$, serum creatinine $<1,25$ Upper Limit of Normal (ULN), serum bilirubin $<1,25$ ULN, GOT or GPT $<2$ ULN), absence of metastases, no prior systemic chemotherapy (CT) or RT to the pelvis, life expectancy $\geq 3$ months. Patients affected by uncompensated cardiopathy or recent acute myocardial infarction, peripheral neuropathy, uncontrolled infection, inflammatory bowel disease or history of another tumour, were excluded. Initial clinical work-up was performed with a digital examination of the anus, rectal wall and recto-vaginal septum, ano-rectal endoscopy and tumor biopsy, chest-abdomino-pelvic CT scan, routine blood tests. The clinical T-stage and nodal involvement were determined by anorectal endoscopic ultrasound (EUS) or by pelvic MRI. Patients with obstructive lesion underwent temporary colostomy before commencement of the study. In all patients a central vein catheter was positioned for chemotherapy delivery. All patients signed a clinical trial informed consent form that was notified to the European Institute of Oncology Ethical Committee.

\section{Treatment protocol}

Radical radiotherapy was delivered by using a high energy linear accelerator ( $\geq 15 \mathrm{MV}$ or mixed energy). Customized blocking for conformal techniques and immobilization system were used in all cases. The gross tumor volume (GTV), clinical target volume (CTV) and planning target volume (PTV) and organs at risk (OARS) were contoured using an Eclipse treatment planning system (Varian Medical Systems, Palo Alto Ca, USA). GTV included the primary tumor and any involved lymph nodes. Two CTVs were considered: a CTV1 which included the GTV, anal canal and a uniform margin of $1 \mathrm{~cm}$; and a CTV2 which included regional lymph nodes at risk such as the external iliac, internal iliac, perirectal, obturator, presacral and the inguinal lymph nodes. PTV 1 and PTV2 were generated by adding a uniform $1.5 \mathrm{~cm}$ margin around the CTV1 and CTV2.

PTV2 is treated up to $36 \mathrm{~Gy}, 1.8$ Gy per fraction, in 22 fractions with anterior and posterior (AP/PA) opposing fields with the superior border of the field at L5/S1 interspace and in nodal positive patients up to $45 \mathrm{~Gy}$ in 25 fractions of $1.8 \mathrm{~Gy}$ with the superior field lowered to the bottom of the sacroiliac joints using either AP/PA fields or a box-technique.

The planning goals were to deliver to the PTV1, via external beam radiotherapy, a dose ranging from a minimum of 41.4 Gy in case of T1-T2 tumors to a maximum of 59.4 in 1.8 Gy per fraction, by using multiplefield technique. Brachytherapy (BRT) was allowed to be administered to the primary tumor either in T1-T2 
patients in order to spare OARs after PTV2 phase completion or in T3 patients with a slow tumor response after the maximum prescription external dose of 59.4 Gy. The large variability in dose prescription and in administration modality reflected the different physicians' attitudes and any eventual treatment adjustment in accordance with patient compliance.

Concurrent chemotherapy containing FU 200 mg/m2 i.v. daily as 24 hours continuous infusion administered via a portable pump through central vein port-a-cath and at least 2 cycles of C $80 \mathrm{mg} / \mathrm{m} 2$ days $1 ; 21$ iv were planned in an outpatient setting. One course was defined as one administration of $C$ plus 3 weeks of c.i. FU.

In patients with T3-T4 or nodal involvement at baseline work-up or in "slow-responder" cases (persistence of local disease with regression $<50 \%$ ) evaluated by at least two physicians at the end of RT, 2 chemotherapy courses were considered. After 6 and within 8 weeks after concomitant chemoradiotherapy, patients underwent tumour reassessment with clinical and instrumental evaluation with ano-rectal EUS and/or pelvic MRI. Tumoral biopses were planned only in case of suspicious progressive local disease. Subsequent tumour evaluation in non-progressive cases was repeated every 3 months for the first 2 years and every 6 months thereafter. Chest and abdominal CT scan was performed every 6 months for 2 years and every 12 months thereafter.

\section{Statistical design}

Response was evaluated according to Word Health Organization (WHO) criteria [4]. Acute toxicity was assessed using the National Cancer Institute Common Toxicity Criteria (NCI-CTC) scale, version 2.0, combined to Radiation Therapy Oncology Group (RTOG) scale; late toxicity using SOMA-LENT scale. Treatment was delayed for toxicity $G>2$ except for nausea or vomiting until G1 or complete recovery. If chemotherapy was delayed more than 3 weeks, the patient was withdrawn. This phase II trial was planned using Simon's Statistical Single Stage Design. For sample size calculation power was assumed as $80 \%$ and type I error (alpha) as $5 \%$. A CR rate of $70 \%$ or smaller was considered unacceptable, whereas a response rate of $90 \%$ or greater was considered sufficient to justify further investigations. The single-stage design required the enrolment of 28 patients; in cases of 24 responses or more the regimen would be considered worthy of further investigations. Descriptive statistics were provided either by median and range for continuous variables or frequency for categorical variables. Response rates and toxicities were summarised by the $95 \%$ confidence interval; interval estimation was provided by the Wilson formulae [5]. Disease-free survival was estimated from the end of chemo-radiotherapy (or date of colostomy when done) to relapse, death or last known follow-up. Overall survival was estimated from the start-time of chemo-radiotherapy to death or last known follow-up. The Kaplan-Meier approach was used for the probability estimation. All analyses were carried out using SAS statistical software (SAS Institute, Cary, NC).

\section{Results}

\section{Patient characteristics}

From June 1999 to June 2008, 29 patients were considered eligible for the study. Main patient characteristics were described in Table 1: stage II 9 patients $(8 \mathrm{~T} 2 / \mathrm{N} 0$ and $1 \mathrm{~T} 3 / \mathrm{N} 0)$, stage III A 14 patients $(1 \mathrm{~T} 1 / \mathrm{N} 1,4 \mathrm{~T} 2 /$ N1, 6 T3/N1, 3 T4/N0) stage IIIB 6 patients $(1 \mathrm{~T} 1 / \mathrm{N} 3$, $1 \mathrm{~T} 4 / \mathrm{N} 1,1 \mathrm{~T} 4 / \mathrm{N} 2,3 \mathrm{~T} 4 / \mathrm{N} 3)$. All patients completed chemo-radiotherapy and were considered evaluable for response. Median duration of CT-RT was 11 weeks (8-17), with a median length of external RT of 49 days

\section{Table 1 Patients' Characteristics}

\begin{tabular}{|c|c|}
\hline Variables & Number \\
\hline Median age (yrs) & 57 (range 40-75) \\
\hline \multicolumn{2}{|l|}{ Gender } \\
\hline Males & $4(14 \%)$ \\
\hline Females & $25(86 \%)$ \\
\hline \multicolumn{2}{|l|}{ Grading } \\
\hline G1 & $1(3 \%)$ \\
\hline G2 & $13(45 \%)$ \\
\hline G3 & $8(28 \%)$ \\
\hline Unknown & $7(24.1 \%)$ \\
\hline \multicolumn{2}{|l|}{ Performance status (ECOG) } \\
\hline 0 & $20(71 \%)$ \\
\hline 1 & $7(25 \%)$ \\
\hline 2 & $1(4 \%)$ \\
\hline Concomitant Pathologies & $15(52 \%)$ \\
\hline \multicolumn{2}{|l|}{ Clinical staging } \\
\hline$\underline{\mathrm{T} 1 \mathrm{~N} 1}$ & $1(3 \%)$ \\
\hline$\overline{\mathrm{T} 1 \mathrm{~N} 3}$ & $1(3 \%)$ \\
\hline$\underline{\mathrm{T} 2 \mathrm{NO}}$ & $8(28 \%)$ \\
\hline$\underline{\mathrm{T} 2 \mathrm{~N} 1}$ & $4(14 \%)$ \\
\hline T3NO & $1(3 \%)$ \\
\hline $\mathrm{T3N1}$ & $6(21 \%)$ \\
\hline$\overline{\mathrm{T} 4 \mathrm{NO}}$ & $3(10 \%)$ \\
\hline$\underline{\mathrm{T} 4 \mathrm{~N} 1}$ & $1(3 \%)$ \\
\hline$\underline{\mathrm{T} 4 \mathrm{~N} 2}$ & $1(3 \%)$ \\
\hline $\mathrm{T4N3}$ & $3(10 \%)$ \\
\hline \multicolumn{2}{|l|}{ Tumor location } \\
\hline$\underline{\text { Anal canal }}$ & $20(71 \%)$ \\
\hline$\underline{\text { Anal canal + anal margin }}$ & $8(28 \%)$ \\
\hline Anal margin & $1(3 \%)$ \\
\hline
\end{tabular}


(range 29-84). The pelvic lymph nodes (PTV2) received a median dose of 41.4 Gy (range 36.0-46.8) through external RT, while the primary tumor and involved nodes received a median dose of 59.4 Gy (range 54.4-74 Gy), either using external RT alone or combined with BRT. With regard to BRT, a median dose of $15 \mathrm{~Gy}$ (range 4-30 Gy) on primary tumor was given to 12 patients after a median interval from the end of RT of 3.2 weeks (range 0.1-5.6). Nine of them were treated by High Dose Rate/Pulsed Dose Rate technique by using a cylindrical applicator while in 3 patients, interstitial implant of BRT was performed under anaesthesia with a perineal template. Total median RT dose in patients with Stage T1 was 59.4 Gy (range 59.4-59.4); T2 62.8 (range 54.4-74); T3 59.4 (56.4-69); T4 59.4 (59,4-70.4). Stage T2 received a larger total dose compared to more advanced tumours: this can be explained by the more frequent use of BRT boost which increases total dose.

\section{Treatment Response}

Two months after the end of chemoradiotherapy, in 27 out of 29 patients (93.1\%; 95\% CI: 78\% - 98\%) CR was documented, while in two patients a stable disease (SD) was reported. One of them presented CR at subsequent tumor assessment, 3 months later and the other progressed after few months. Two patients were diverted pre-treatment due to local disease extension and one of them underwent successful reversal after nine months from the end of RT; in the remaining one, persistent anal sphincter incontinence was observed. During treatment in one case colostomy was considered due to subocclusion determined by treatment-related congestive tumour response. After chemoradiotherapy two patients underwent abdominal perineal resection for local disease persistence, but in one case no residual tumour was documented in the surgical specimen. The rate of colostomy was $14 \%$. The 1 -year and the estimated 7 -year colostomy-free survival were $85.9 \%$ (C.I. $73.1 \%$ 98.7\%). Over time three patients with CR, exhibited systemic relapse at 4 and 34 months. One patient died and the other is still alive at 19 months since evidence of relapse. After a median follow up of 42 months (range: 4-81), 25 patients are still alive without relapse, 1 patient is alive with relapse and 3 patients died due to PD. The estimated 3, 5 and 7-year DFS were 83.4\% (C.I. 68.3\%98.5\%) and the estimated 3-year OS was 92.3 (range $82 \%-100 \%$ ) and 5 and 7 -year OS were $85.7 \%$ (C.I. $70 \%$ $100 \%$ ) (Figure 1; Figure 2).

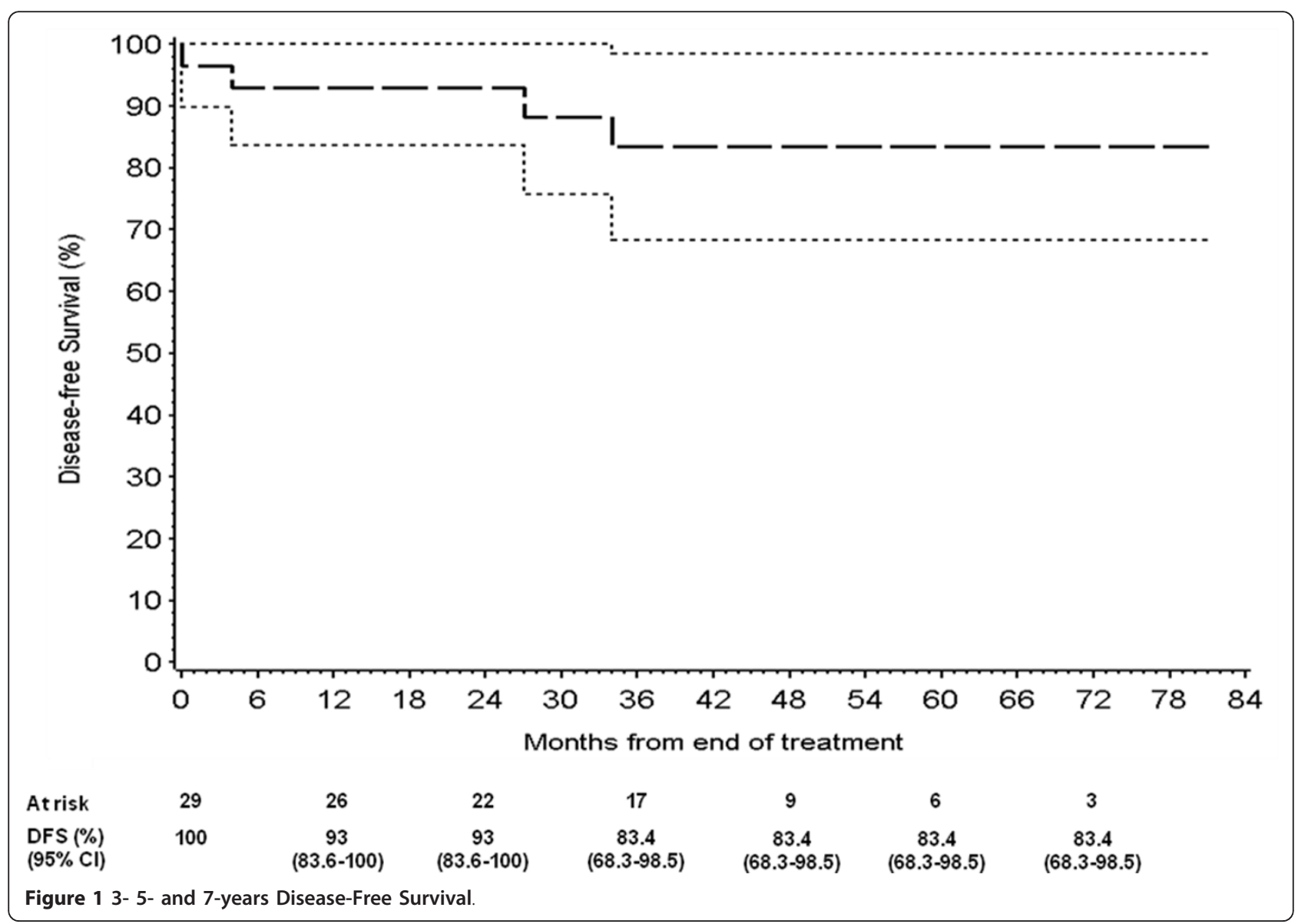




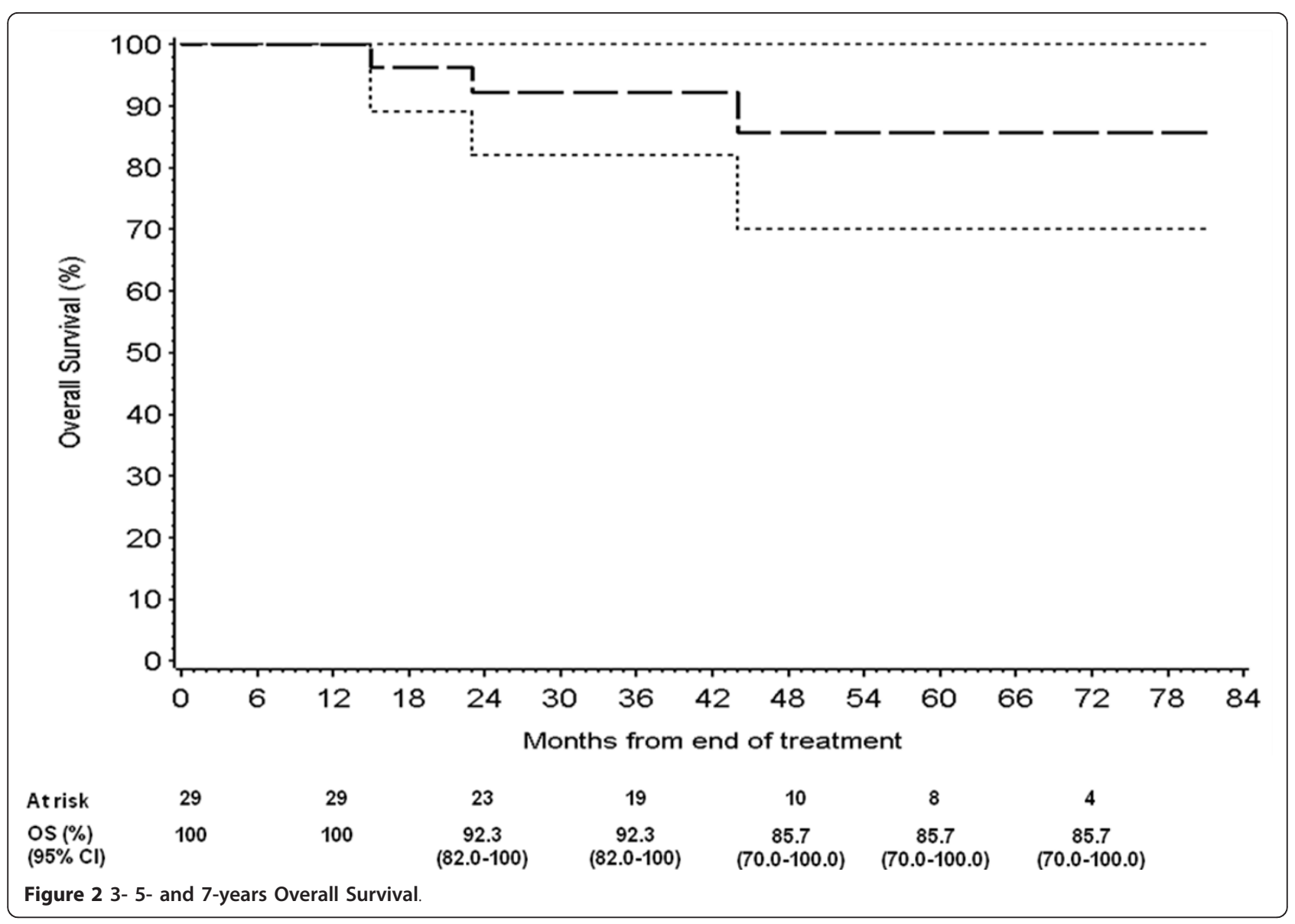

DFS for patients who underwent a colostomy without evidence of disease, was censored at the date of colostomy.

\section{Delivered Treatment and Toxicity}

During treatment 14 patients discontinued chemoradiotherapy due to RT side effects, which lasted with as median 9 days (range 1-39) (Table 2). No chemotherapy delay more than 3 weeks was observed. At the $2^{\text {nd }}$ month, 11 patients reported toxicities mostly related to RT; two events were classified as G3-G4 (1 proctitis and 1 rectal bleeding). Concerning chemotherapy a total of 98 cycles were administered: FU was given in 97, while $\mathrm{C}$ was given in 94. (Table 3 ) $\mathrm{FU}$ and $\mathrm{C}$ were given together in 93 courses and in 62 without delays/modifications; in 4 cases and $1, \mathrm{FU}$ and $\mathrm{C}$ were given as single agent, respectively. All patients received at least 2 cycles of C: 5 patients (17.2\%) received two cycles, 12 patients (41.4\%) three and 12 patients (41.4\%) four cycles. The rate of patients who performed 4 cycles was $21.4 \%$ among $\mathrm{T} 1 / \mathrm{T} 2 ; 57.1 \%$ among $\mathrm{T} 3$ and $62.5 \%$ among $\mathrm{T} 4$ stage. In 70 cycles out of 94 (74.5\%) CT full dose-intensity was administered.
Focusing on the first two mandatory cycles, 20 patients out of 29 received a full-intensity dose while in 9 patients the $2^{\text {nd }}$ cycle was delayed or modified due to 1 G3 neutropenia and 2 G1-2 leucopoenia, 6 G2-G3 non-haematological toxicities. At 6 months after the end of RT, 6 patients did not exhibit any treatment related toxicity. Most frequent late events G3-G4 occurred in 14 patients: proctitis (5), dermatitis (4) bladder dysfunctions (2), sexual dysfunctions (9), low extremities venous thromboses (2), dysuria (1), stenosis (1) and tenesmus (1). Five patients reported G1 leucopoenia (Table 4).

\section{Discussion}

Concurrent chemoradiotherapy is the standard treatment for localized anal cancer, while surgical resection has been reserved as salvage strategy only for persistent disease and for local relapse. However, it often fails to control spread of the disease. With $\mathrm{M}$ and FU containing CT-RT $60-90 \%$ local control rates and $60-70 \%$ 5 -year survival rates were reported, with infrequent need for colostomy $[1,6,7]$.

Mitomycin added to FU shows improved results in terms of local control and time to colostomy in 3 
Table 2 RT on-treatment toxicity

\begin{tabular}{ll}
\hline Variables & Number \\
\hline & 29 \\
\hline No of patients with at least 1 toxicity & $29(100 \%)$ \\
Maximum grade toxicity & \\
G2 & 16 \\
G3 & 12 \\
G4 & 1 \\
\hline No of side effects & 95 \\
G1 & 17 \\
G2 & 63 \\
G3 & 14 \\
G4 & 1 \\
\hline No. of patients with gastrointestinal toxicity & $26(89.7 \%)$ \\
No. of Gl side effects & 49 \\
Abdominal pain & $5(2)^{*}$ \\
Diarrhoea & $14(1)^{*}$ \\
Mucorrhea & 6 \\
Nausea/vomiting & 6 \\
Proctitis & 6 \\
Rectal bleeding & 2 \\
Rectal pain & 4 \\
Constipation & $26(37.9 \%)$ \\
Tenesmus & 35 \\
\hline No. of patients with genito-urinary toxicity & $10(37.9 \%)$ \\
No. of GU side effects & 11 \\
Dysuria & $11(3)^{*}$ \\
\hline No. of patients with other toxicities & \\
No. of Other toxicities & 2 \\
Dermatitis & 11 \\
Mucositis & 17 \\
\hline & parthes \\
\hline
\end{tabular}

*In parentheses the number of G3-G4 events.

randomized trials compared to $\mathrm{RT}$ alone and $\mathrm{RT}$ plus FU as single agent $[2,8,9]$. Unfortunately $\mathrm{M}$ can cause severe, life-threatening haematological adverse events (18\%), lung toxicity, and haemolytic-uremic syndrome.

Alternative regimens containing $\mathrm{C}$, cytotoxic agent with considerable interest as a radiation sensitizer, have been investigated in phase II trials, even if no definite role of this agent is well determined by now (Table 5) [6,10-13].

In our phase II trial the role of early C-containing chemotherapy and concurrent radiotherapy followed by the same regimen administered for one or two courses, was investigated in order not to delay RT, considered as an irreplaceable therapeutic procedure in the treatment of anal SCC and in order to evaluate additional therapy in high risk cases. In this population of patients, 93.1\%; (95\% CI: $78 \%-98 \%$ ) of CR was reported at 2 months with an estimated DFS of $83.4 \%$ (68.3\%-98.5\%) and estimated 7-years OS of $85.7 \%$ (70\% - 100\%). These data confirm the efficacy of $\mathrm{C}$-containing schemes as
Table 3 Chemotherapy characteristics and on-treatment toxicities

\begin{tabular}{|c|c|}
\hline Variables & Number \\
\hline Total number of cycles & 98 \\
\hline Fluorouracil & $97 \wedge$ \\
\hline Cisplatin & $94^{*}$ \\
\hline \multicolumn{2}{|l|}{ Patients receiving } \\
\hline 2 cycles & $\begin{array}{l}5 \\
(17.2 \%)\end{array}$ \\
\hline 3 cycles & $\begin{array}{l}12 \\
(41.4 \%)\end{array}$ \\
\hline 4 cycles & $\begin{array}{l}12 \\
(41.4 \%)\end{array}$ \\
\hline \multicolumn{2}{|l|}{ Cisplatin modification (total \# of cycles $=94$ ) } \\
\hline Full dose-intensity & $\begin{array}{l}70 \\
(74.5 \%)\end{array}$ \\
\hline Delay/modification & 24 \\
\hline \multicolumn{2}{|l|}{$\begin{array}{l}\text { Cisplatin and/or Fluorouracil modification (total \# of cycles } \\
\text { over the first } 2 \text { cycles }=58 \text { ) }\end{array}$} \\
\hline Full dose-intensity & $\begin{array}{l}49 \\
(70.7 \%)\end{array}$ \\
\hline Delay/modification & 9 \\
\hline \multicolumn{2}{|l|}{ Reasons } \\
\hline Haematological toxicities & 2 \\
\hline Neutropenia (G3) & 1 \\
\hline Leucopoenia (G1) & 1 \\
\hline Non Haematological toxicities & 5 \\
\hline Diarrhoea (G2) & 1 \\
\hline Nausea (G2 and G3) & 2 \\
\hline Nausea and Diarrhoea (G2) & 1 \\
\hline Mucositis (G2) & 1 \\
\hline Haematological and non-haematological toxicities & 1 \\
\hline Diarrhoea (G2) and Leucopoenia (G2) & 1 \\
\hline Other toxicities & 1 \\
\hline Hypoacusia (G2) & 1 \\
\hline
\end{tabular}

$\wedge 1$ patient received $C$ only.

*5 patients received Fluorouracil only.

previously reported in phase II trials. The results of our study might be related to better radiosensitizer action of FU administered as continuous infusion and to tailored consolidation CT courses delivered in cases of high risk baseline stage and 'slow response' after concomitant chemo-radiotherapy. As for colostomy on 27 evaluable patients (two patients had colostomy before treatment), 3 patients (11\%) derived during or after chemo-radiotherapy. Concerning acute toxicity, we observed perineal mucosa and skin side effects of grade $3-4$ in about $40 \%$ of patients, similar to previously reported literature data (Table 4). Grade 3-4 diarrhoea was observed in less than $5 \%$ of patients, with a lower incidence compared to that reported by older series $(30-44 \%)[9,14,15]$. The modern use of 3D conformal RT with optimized protection of normal tissues, the technique of shrinking fields, and 
Table 4 Late toxicity

\begin{tabular}{llll}
\hline \multicolumn{4}{l}{ Number of Events } \\
\hline Variables & Grade 1-2 & Grade 3 & Grade 4 \\
\hline Dysuria/Incontinence & $2 / 4$ & $2 /-$ & $-/ 1$ \\
\hline Abdominal Pain & 4 & - & - \\
\hline Rectal Pain & 4 & 1 & - \\
\hline Bleeding & 10 & - & - \\
\hline Ulceration & - & 3 & 1 \\
\hline Anorectal Stenosis & - & 1 & - \\
\hline Female Sexual Dysfunction & 15 & 10 & 8 \\
\hline Male Sexual Dysfunction & - & 1 & - \\
\hline Deep Venous Thrombosis & - & 2 & - \\
\hline Bone Fracture & - & 1 & - \\
\hline Leucopoenia & 5 & - & - \\
\hline
\end{tabular}

devices for sparing the small bowel may clearly contribute to reduce these side effects $[15,16]$. The literaturereported rate of late toxicity, varies from $4 \%$ to $50 \%$ depending on follow-up length, radiation treatment parameters such as RT technique and fraction site, and chemotherapeutic agents combination [17]. In our series 23 patients had at least one G2, while 15 at least one G3-
G4 late toxicity. The highest toxicity rate was the rectal one (16 patients), with G3 reported in 5 patients. Among other G3-G4 toxicity, we observed 10 cases of sexual dysfunction ( $9 \mathrm{~F}$ and $1 \mathrm{M}$ ), 5 anal ulceration, 4 dermatitis, 3 urinary events, 1 vulvo-vaginitis, 1 bone fracture. Toxic late events reported in our series seem to be similar to previous reported literature data, except for sexual discomfort which was often not described [6,10-12]. Intracavitary or interstitial RT was used to deliver a boost to the tumor bed, while sparing surrounding normal structures.

The incidence of $G \geq 2$ late side effects was higher in patients receiving a boost with external RT than those receiving it by BRT: among the 12 BRT patients, 5 (41.7\%) suffered from side effects higher than G2 as maximum toxicity compared to 10 out of 17 patients (58.8\%) in external RT group. In particular, all the BRT boost patients experienced a lower bladder toxicity (8.3\% vs. $41.2 \%$, p 0.05$)$ and a slight higher rectal toxicity (58.3 vs. 52.9 , p 0.77 ) compared external RT boost patients. In the BRT boost group, no relationship between rectal maximum toxicity and total dose was found, $G \geq 2$ toxicity was observed in all 3 patients treated with interstitial modality and in 3 out of 9 patients treated with intracavitary modality.

Table 5 Cisplatin-containing Phase II Trials

\begin{tabular}{|c|c|c|c|c|}
\hline Author & $\begin{array}{l}\text { Trial, Total number } \\
\text { patients and Stage }\end{array}$ & Regimen & Response & Toxicity $\geq$ G3 \\
\hline Martenson, 1996 & $\begin{array}{l}\text { Phase II: } 19 \text { pts } \\
\text { T1-4/N0-3/M0 }\end{array}$ & $\begin{array}{l}2 \text { cycles FU } 1000 \mathrm{mg} / \mathrm{m} 2 \times 4 \text { days, } \\
\text { CDDP } 75 \mathrm{mg} / \mathrm{m} 2 \text { concomitant to RT } 59.4 \text { Gy }\end{array}$ & $\begin{array}{l}15 \text { CR }(79 \%) ; \\
4 \text { PR }(21 \%) \\
\text { Colostomy rate: na DFS: na } \\
\text { OS: na }\end{array}$ & $\begin{array}{l}\text { G3-4: } \\
\text { haematological 50\% } \\
\text { diarrhoea } 20 \% \\
\text { skin } 20 \% \\
\text { G5: } 1 \text { infection }\end{array}$ \\
\hline Doci, 1996 & $\begin{array}{l}\text { Phase II: } \\
35 \text { pts } \\
\text { T1-T3/N1-3/M0 }\end{array}$ & $\begin{array}{l}2-3 \text { cycles } \\
\text { FU } 750 \mathrm{mg} / \mathrm{m} 2 \times 4 \text { days, } \\
\text { CDDP } 100 \mathrm{mg} / \mathrm{m} 2 \\
\text { concurrent RT } 36-38 \text { Gy }\end{array}$ & $\begin{array}{l}33 \text { CR }(94 \%) \\
2 \text { PR }(6 \%) \\
\text { Median follow-up } 37 \text { mos. } \\
\text { colostomy free } 86 \% \\
\text { OS } 94 \%\end{array}$ & $\begin{array}{l}\text { G3: } \\
\text { Diarrhoea 2-3\% } \\
\text { skin 2-3\% }\end{array}$ \\
\hline Gerard, 1998 & $\begin{array}{l}\text { Phase II: } 95 \text { pts } \\
\text { T1-4/N0-3/M0 }\end{array}$ & $\begin{array}{l}1 \text { cycle FU } 1000 \mathrm{mg} / \mathrm{m} 2 \times 4 \text { days, } \\
\text { CDDP } 25 \mathrm{mg} / \mathrm{m} 2 / \mathrm{d} \times 4 \text { days concomitant } \\
\text { to RT followed by a boost with } 192 \mathrm{lr} \text { implant. }\end{array}$ & $\begin{array}{l}85 \text { CR }(89 \%) \\
7 \text { PR (8\%) } \\
\text { Median follow-up } 64 \text { mos. } \\
5 y \text { colostomy free } 71 \% \\
5 y O S 84 \%\end{array}$ & $\begin{array}{l}\text { G3: } \\
\text { haematological 3\% } \\
\text { TVP } 1 \%\end{array}$ \\
\hline Peiffert, 2001 & $\begin{array}{l}\text { Phase II: } 80 \text { pts } \\
\text { T1-4/N0-3/M0 }\end{array}$ & $\begin{array}{l}2 \text { neoadjuvant and } 2 \text { cycles } \\
\text { FU } 800 \mathrm{mg} / \mathrm{m} 2 \times 4 \text { days, } \\
\text { CDDP } 80 \mathrm{mg} / \mathrm{m} 2 \\
\text { concomitant to RT } 45 \mathrm{~Gy}\end{array}$ & $\begin{array}{l}70 \text { CR } 70(87 \%) \\
4 \text { PR }(5 \%) \\
\text { At } 3 \text { year: colostomy-free } 73 \% \text {; } \\
\text { OS } 86 \%\end{array}$ & $\begin{array}{l}\text { G3-G4: } \\
\text { angina pectoris 2\% } \\
\text { mucositis 16\% } \\
\text { diarrhoea 16\% } \\
\text { skin 32\% } \\
\text { G5: } 1 \text { TEP }\end{array}$ \\
\hline Cho, 2008 & $\begin{array}{l}\text { Phase II: } 31 \text { pts } \\
\text { T1-4/N0-3/M0 }\end{array}$ & $\begin{array}{l}2 \text { cycles } \\
\text { FU } 750-1000 \mathrm{mg} / \mathrm{m} 2 \text { days } 1-5 \\
\text { CDDP } 75-100 \mathrm{mg} / \mathrm{m} 2 \\
\text { concomitant to RT } 45 \text { Gy } \\
\rightarrow 2 \text { consolidation cycles FU +CDDP }\end{array}$ & $\begin{array}{l}31 \text { CR }(90.3 \%) \\
4 \text { PR }(9.7 \%) \\
\text { Median follow-up } 72 \text { mths; } \\
\text { DFS } 82.9 \% \\
\text { OS } 84.7 \%\end{array}$ & $\begin{array}{l}\text { G3-G4: } \\
\text { skin 55\% } \\
\text { neutropenia 33\% } \\
\text { infection 3.2\% } \\
\text { fatigue } 4.8 \%\end{array}$ \\
\hline Zampino, Current work & $\begin{array}{l}\text { Phase II: } \\
29 \text { pts } \\
\text { T1-4/N0-3/M0 }\end{array}$ & $\begin{array}{l}\text { 2-4 cycles } \\
\text { FU } 200 \mathrm{mg} / \mathrm{m} 2 \text { i.c } \\
\text { CDDP } 75 \mathrm{mg} / \mathrm{m} 2 \text { day } 1 / 21 \\
\text { concomitant to RT } 45-74 \text { Gy }\end{array}$ & $\begin{array}{l}\text { Median follow-up } 7 \text { yrs; } \\
\text { CR 93\% } \\
\text { DFS } 85 \% \\
\text { OS } 86 \%\end{array}$ & $\begin{array}{l}\text { G3-G4: } \\
\text { mucositis 10\% } \\
\text { diarrhoea 3\% } \\
\text { skin 31\% } \\
\text { Hematological 3\% }\end{array}$ \\
\hline
\end{tabular}


Recently the impact of $\mathrm{C}$ as an attractive drug was investigated in phase III trials with the aim to evaluate neoadjuvant treatment before concomitant chemoradiotherapy [7,18-20]. In the Intergroup RTOG 98-11 phase III trial the comparison was evaluated between $\mathrm{C}$ plus FU induction treatment followed by the same chemotherapy and concurrent radiation and $\mathrm{M}$ plus FU and concurrent radiation: $\mathrm{C}$-based therapy failed to improve disease-free-survival compared with $\mathrm{M}$-control arm, and resulted in a significantly worse colostomy rate (19\% vs $10 \%)$; severe hematological toxicity was confirmed to be worse with the M-containing arm [7].

It must be emphasized that the RTOG 98-11 trial was not a pure comparison of concurrent chemoradiation with $\mathrm{C}$ plus FU versus $\mathrm{M}$ plus FU but, rather, was a comparison of one strategy versus another. The assumption that the strategy of induction chemotherapy had been able to reduce the bulk of local-regional anal SCC was not supported by the results documented in randomized study.

Also in the ACCORD 03 trial neoadjuvant role of C-FU was investigated [19] Early data on quality of life has already been published [20]. Combination of $C$ and $M$ was also evaluated in a phase III trial and compared to conventional FU-M concomitant to RT: local control was reported in $89 \%$ vs $74 \%$, respectively with acceptable toxicity [21].

At the moment these results do not support the use of C-based neoadjuvant chemotherapy followed by chemoradiotherapy in place of $\mathrm{M}$ in combination with $\mathrm{FU}$ and radiotherapy in the treatment of anal canal carcinoma.

\section{Conclusions}

The promising results obtained in present study even though observed in a limited number of patients, seemed to be suitable for future investigation with the aim to confirm the possible use of early administered $\mathrm{C}$-containing treatment with radiotherapy and to evaluate the advantage of sequential chemotherapy after chemoradiotherapy in high risk patients with anal SCC.

Further research into molecular biology related to disease progression and resistance to chemoradiotherapy may provide a better understanding of different pattern of anal carcinoma and may also support the clinical use of biologic agents. Future investigations will be directed towards the evaluation of new cytotoxic agents such as taxanes or targeted drugs such as anti-epidermal growth factor receptor, concomitant to RT and to determining the role of intensity-modulated radiotherapy [22,23].

\footnotetext{
Author details

${ }^{1}$ Medical Care Unit, Department of Medicine, European Institute of Oncology, via Ripamonti 435, Milan 20141, Italy. ${ }^{2}$ Radiotherapy Division, European Institute of Oncology, via Ripamonti 435, Milan 20141, Italy. ${ }^{3}$ Epidemiology and Biostatistics Division, European Institute of Oncology, via
}

Ripamonti 435, Milan 20141, Italy. ${ }^{4}$ Radiology Division, European Institute of Oncology, via Ripamonti 435, Milan 20141 Italy. ${ }^{5}$ Endoscopy Division, European Institute of Oncology, via Ripamonti 435, Milan 20141, Italy. ${ }^{6}$ University of Milan, via Ramusio 1, Milan 20141, Italy.

\section{Authors' contributions}

$M Z, E M, C L$ made substantial contributions to the conception and design, acquisition analysis and interpretation of data; were involved in drafting the manuscript and gave final approval of the version to be published. EP, CT, GP made substantial contributions to the conception and design, acquisition analysis and interpretation of data. CF made substantial contributions to acquisition analysis and interpretation of data. LS participated in the design of the study and performed the statistical analysis. FN, RO were involved in revising the manuscript for important intellectual content. All authors read and approved the final manuscript.

\section{Competing interests}

The authors declare that they have no competing interests.

Received: 24 August 2010 Accepted: 3 February 2011

Published: 3 February 2011

\section{References}

1. Nigro ND, Seydel HG, Considine B, Vaitkevicius VK, Leichman L, Kinzie JJ: Combined preoperative radiation and chemotherapy for squamous cell carcinoma of the anal canal. Cancer 1983, 51(10):1826-9.

2. Flam M, John M, Pajak TF, Petrelli N, Myerson R, Doggett S: Role of mitomycin in combination with fluorouracil and radiotherapy, and of salvage chemoradiation in the definitive nonsurgical treatment of epidermoid carcinoma of the anal canal: Results of a phase III randomized Intergroup study. J Clin Oncol 1996, 14:2527-2539.

3. Fuchshuber PR, Rodriguez-Bigas M, Weber T, Petrelli NJ: Anal canal and perianal epidermoid cancers. J Am Coll Surg 1997, 185(5):494-505.

4. Geneva (Switzerland): WHO handbook for reporting results of cancer treatment. World Health Organization Offset Publication 1979, 48.

5. Wilson EB: Probable inference, the law of succession, and statistical inference. J Am Stat Assoc 1972, 22:209-212.

6. Peiffert D, Giovannini $M$, Ducreux M, Michel P, Francois E, Lemanski C, Mirabel X, Cvitkovic F, Luporsi E, Conroy T, Gérard JP, Digestive Tumours Group of the French 'Fédération Nationale des Centres de Lutte Contre le Cancer': High-dose radiation therapy and neoadjuvant plus concomitant chemotherapy with 5 -fluorouracil and cisplatin in patients with locally advanced squamous-cell anal carcinoma: Final results of a phase II study. Ann Oncol 2001, 12:397-404.

7. Ajani JA, Winter KA, Gunderson LL, Pedersen J, Benson AB, Thomas CR, Mayer RJ, Haddock MG, Rich TA, Willet C: Fluorouracil, mitomycin, and radiotherapy vs fluorouracil, cisplatin, and radiotherapy for carcinoma of the anal canal: A randomized controlled trial. JAMA 2008, 299:1914-1921.

8. UKCCCR Anal Cancer Working Party: Epidermoid anal cancer: Results from the UKCCCR randomised trial of radiotherapy alone versus radiotherapy, 5-fluorouracil and mitomycin c. Lancet 1996, 348:1049-1054.

9. Bartelink H, Roelofsen F, Eschwege F, Rougier P, Bosset JF, Gonzalez DG, Peiffert D, van Glabbeke M, Pierart M: Concomitant radiotherapy and chemotherapy is superior to radiotherapy alone in the treatment of locally advanced anal cancer: Results of a phase III randomized trial of the European Organization for Research and Treatment of Cancer Radiotherapy and Gastrointestinal Cooperative Groups. J Clin Oncol 1997, 15:2040-2049.

10. Martenson S, Lipsitz H, Wagner Kaplan EH, Otteman LA, Schunther LM: Initial results of a phase II trial of high dose radiation therapy, 5-fluorouracil, and cisplatin for patients with anal cancer (E4292): An Eastern Cooperative Oncology Group study. Int J Radiat Oncol Biol Phys 1996, 35:745-749.

11. Doci R, Zucali R, La Monica G, Meroni E, Kenda R, Eboli M, Lozza L: Primary chemoradiation therapy with fluorouracil and cisplatin for cancer of the anus: results in 35 consecutive patients. J Clin Oncol 1996, 14:3121-5.

12. Gerard JP, Ayzac L, Hun D, Romestaing P, Coquard R, Ardiet J, Mornex F: Treatment of anal canal carcinoma with high dose radiation therapy and concomitant fluorouracil-cisplatin. Long-term results in 95 patients. Radiother Oncol 1998, 46:249-256.

13. Cho BC, Ahn JB, Seong J, Roh JK, Kim JH, Chung HC, Sohn JH, Kim NK: Chemoradiotherapy with or without consolidation chemotherapy using 
Cisplatin and 5-Fluorouracil in anal squamous cell carcinoma: long-term results in 31 patients. BMC Cancer 2008, 15:8:8.

14. Weber DC, Kurtz JM, Allal AS: The impact of gap duration on local control in anal canal carcinoma treated by split-course radiotherapy and concomitant chemotherapy. Int I Radiat Oncol Biol Phys 2001, 50:675-680.

15. Myerson RJ, Kong F, Birnbaum EH, Fleshman JW, Kodner IJ, Picus J, Ratkin GA, Read TE, Walz BJ: Radiation therapy for epidermoid carcinoma of the anal canal clinical and treatment factors associated with outcome. Radiother Oncol 2001, 61:15-22, 2001.

16. Deo SV, Shukla NK, Raina V, Mohanti BK, Sharan R, Kar M, Rath GK: Organpreserving multimodality management of squamous cell carcinoma of anal canal. Int J Gastroenter 2005, 24:201-204.

17. Vuong T, Devic S, Belliveau P, Muanza T, Hegyi G: Contribution of conformal therapy in the treatment of anal canal carcinoma with combined chemotherapy and radiotherapy: results of a phase II study. Int J Radiat Oncol Biol Phys 2003, 56:823-831.

18. James R, Meadows H, Wan S: ACT II: The second UK phase III anal cancer trial. Clin Oncol (R Coll Radiol) 2005, 17:364-366.

19. Peiffert D, Gerard JP, Ducreux M, Lemanski C, François E, Giovannini Cvitkovic F, Mirabel X, Bouchè O, Luporsi E: Induction chemotherapy (ICT) and dose intensification of the radiation boost in locally advanced anal cancer (LAACC): Interim analysis of the 101 first randomized patients (pts) in the Intergroup ACCORD 03 trial (Federation Nacionale des Centres de Lutte Contre le Cancer - Fondation Francaise de Cancerologie Digestive). Eur J Cancer 2005, 2:172, (suppl 3; abstr 614).

20. Tournier-Rangeard L, Mercier M, Peiffert D, Gerard JP, Romestaing $P$, Lemanski C, Mirabel X, Pommier P, Denis B: Radiochemotherapy of locally advanced anal canal carcinoma: Prospective assessment of early impact on the quality of life (randomized trial ACCORD 03). Radiother Oncol 2008, 87:391-397.

21. Matzinger O, Roelofsen F, Mineur L, Koswig S, Van Der Steen-Banasik EM, Van Houtte P, Haustermans K, Radosevic-Jelic L, Mueller RP, Maingon P, Collette L, Bosset JF, For the EORTC Radiation Oncology and Gastrointestinal Tract Cancer Groups: Mitomycin C with continuous fluorouracil or with cisplatin in combination with radiotherapy for locally advanced anal cancer (European Organisation for Research and Treatment of Cancer phase II study 22011-40014). Eur J Cancer 2009, 45(16):2782-91.

22. Glynne-Jones R, Mawdsley S: Anal cancer: the end of the road for neoadjuvant chemoradiotherapy? J Clin Oncol 2008, 26:3669-3671.

23. Saarilahti K, Arponen P, Vaalarvirta L, Tenhunen M: The effect of intensitymodulated radiotherapy and high dose rate brachytherapy on acute and late radiotherapy-related adverse events following chemoradiotherapy of anal cancer. Radiother Onco / 2008, 87:383-390.

Pre-publication history

The pre-publication history for this paper can be accessed here: http://www.biomedcentral.com/1471-2407/11/55/prepub

doi:10.1186/1471-2407-11-55

Cite this article as: Zampino et al:: Concurrent cisplatin, continuous infusion fluorouracil and radiotherapy followed by tailored consolidation treatment in non metastatic anal squamous cell carcinoma. BMC Cancer 2011 11:55.

\section{Submit your next manuscript to BioMed Central and take full advantage of:}

- Convenient online submission

- Thorough peer review

- No space constraints or color figure charges

- Immediate publication on acceptance

- Inclusion in PubMed, CAS, Scopus and Google Scholar

- Research which is freely available for redistribution

Submit your manuscript at www.biomedcentral.com/submit
Biomed Central 